\title{
Giving a Socially Distanced Voice to Disabled Young People: Insights from the Educational Pathways and Work Outcomes Longitudinal Study
}

\author{
Angharad Butler-Rees \\ Department of Sociology \\ University of Warwick \\ angharad.butler-rees@warwick.ac.uk
}

\author{
Stella Chatzitheochari \\ Department of Sociology \\ University of Warwick \\ s.chatzitheochari@warwick.ac.uk
}

The COVID-19 pandemic has created unprecedented challenges for social research. However, little is known about the impact of social distancing measures on research with hard-to-reach populations. This paper provides methodological reflections on the efficacy of socially distanced recruitment and interviewing methods for research with disabled young people, drawing on our experience from the Educational Pathways and Work Outcomes longitudinal study, which started in March 2021 during the third national lockdown in England. We discuss difficulties in gaining access to disabled young people and argue that the pandemic has exacerbated longstanding barriers implicated in the recruitment of hard-to-reach populations who are typically seen as vulnerable by gatekeepers. In contrast, our experience suggests that flexible online/virtual interviews can overcome pitfalls inherent in the face-to-face interviewing of disabled young people and could therefore be utilised to make their voices heard in a variety of contexts and scenarios after the end of the ongoing pandemic.

Keywords: disability, young people, recruitment, gatekeeping, online interviewing 


\section{Introduction}

Recent decades have witnessed a reconceptualisation of children and young people as active social agents (Beresford, 1997; Hill, 1997), as part of the broader discourse about human rights and childhood. The view of children and young people as "beings not becomings" (Qvotrup, 1994:2) led to the gradual abandonment of research paradigms that understood childhood and adolescence in strictly paediatric and pedagogical terms (Levine, 2007) and relied on parents, teachers and/or psychologists as knowledge experts (Christensen \& James, 2000). Longstanding ideas about children and young people's inability to provide accurate accounts of their experiences were called into question, while ethical guidelines for safeguarding them during the research process were put into place (Kirk, 2007). As a result, innovative methodological approaches that recognised children and young people as experts of their own lives have gained ground in the social sciences (Holt \& Evans, 2017).

Considered as doubly vulnerable, the voices of disabled children and young people had been particularly side-lined in research, with an ensuing gap of knowledge surrounding lived experiences of disability at early life-course stages (Watson, 2012). The resistance to consider disabled children and young people as legitimate research participants is closely linked to persisting ableist assumptions surrounding competency (Stafford, 2017; Wickenden \& Kembhavi-Tam, 2014), which overlook the vast heterogeneity within constructed disability categories (Powell, 2003). Despite the growth of empirical studies and methodologies that challenge the marginalisation of these populations in research (Holt \& Evans, 2017; Jenkin et al., 2020; Liddiard et al., 2018; Stafford, 2017; Wickenden \& Kembhavi-Tam, 2014), there remain ableist attitudes and barriers that impede inclusive approaches in this field of enquiry. 
The COVID-19 pandemic has created additional challenges, necessitating the use of socially distanced recruitment and interviewing research methods. In this paper, we provide a methodological reflection on the efficacy of these methods and assess the extent to which they can be utilised to give a platform to disabled young people to describe their experiences in their own words. This is particularly important given that disabled young people's voices have readily been overlooked in favour of those of their parents/guardians and professionals.

\section{Literature Review}

Although rates of childhood and adolescent disability have been increasing globally (Halfon et al., 2012), disabled children and young people remain hard-to-reach groups. Scholars note that gatekeepers' understandings of childhood and/or disability may ultimately inhibit children and young people's engagement with research (Campbell, 2008; Kirk, 2007; Williams, 2020). The sensitive and highly politicised topic of special educational needs provision in schools also means that specialist gatekeepers (e.g., headteachers and Special Educational Needs and Disabilities Coordinators - SENDCos ${ }^{1}$ ) who can facilitate access to disabled participants, may perceive research projects as threatening to reveal practices that they do not wish to see represented within the public domain (Clark, 2010). Gatekeepers may also decline cooperation if they consider disabled groups to be over-researched. Increased research tenacity is thus required, as well as the use of various types of gatekeepers to achieve a sufficient sample size. Similar to research on other hard-to-reach populations (Abrams, 2010; Meyer \& Wilson, 2009), disability studies tend to rely on convenience and snowball sampling procedures, which often yield relatively small and self-selected samples of children and young people. 
We know little about the influence of the COVID-19 pandemic on the recruitment of disabled children and young people for research. We expect that the exclusive reliance on technological means for recruitment may act as a barrier, undermining relationships with gatekeepers due to lack of physical co-presence and impeding access to disabled children and young people from socially disadvantaged backgrounds who are less likely to have access to technology/the internet and account for the majority of this population (Parsons \& Platt, 2013). It is also important to note that key gatekeepers, that is, teachers, SENDCos and parents, have been disproportionately affected by the pandemic, experiencing a substantial increase in working hours and stress levels (Ashbury et al., 2021, Kim \& Ashbury 2020), which can negatively affect their willingness to support research. Similarly, gatekeepers are likely to decline participation due to concerns around the impact of the pandemic and homeschooling on students' mental health and wellbeing (Cowie \& Myers, 2020).

Existing research confirms that, once recruited for a research project, disabled children and young people are capable of acting as independent participants (Brady \& Franklin 2019; Teachman \& Gibson, 2013). Brady \& Franklin (2019) have, for example, incorporated disabled young people as co-investigators, involved in decision-making and in formulating the research agenda. Many other studies use creative and participatory methods (Liddiard et al., 2018; McLaughlin \& Coleman-Fountain, 2019; Wickenden \& Kembhavi-Tam, 2014). Creative methods include activities such as photography and videography, while participatory methods are based upon the notion of researching "with" as opposed to "on" children and young people (Holt \& Evans, 2017). While these approaches have produced interesting insights, they have been criticised for disregarding children and young people's position as independent actors by assuming that they are unable to engage with conventional research tools such as interviews or focus groups (Hill, 1997; Punch \& Graham, 2017). Additionally, 
scholars have problematised the idea that these methods give access to a truth not accessible by conversational methods (Harden et al., 2000).

Less is known about the ways disabled children and young people engage with interview methods, which can produce rich uninterrupted accounts of lived experience. Such data collection methods are more relevant for disabled young people, who have received less methodological attention compared to younger children and adults and constitute the focus of our paper. As McDowell (2001) notes, creative methods aimed towards younger children may be seen as "childish" by young people. However, there is evidence that some young people may not feel comfortable with conversational methods typically used with adults (Bassett et al., 2018). This may be more common among disabled young people who are less used to speaking for themselves (Wickenden \& Kemhavin-Tan, 2014). Disabled interviewees are also more likely to experience respondent fatigue, particularly those with certain impairments/conditions (Carlsson et al., 2007; Whitehurst, 2006). However, the nature of traditional interviewing methods allows researchers to provide participants with an outline of key questions in advance, which can be particularly beneficial for this population. More generally, it has been shown that the use of semi-structured interviews tailored to disabled young people's needs and preferences can facilitate greater engagement (Preece \& Jordan, 2010; Shepherd, 2015).

There is also paucity of information surrounding the effectiveness of online communication platforms for interviewing disabled young people. This is an important methodological omission given that online interviews can potentially resolve issues of accessibility present in the face-to-face interviewing of disabled people through incorporating assistive technology e.g., subtitling and magnification (Topping et al., 2021), and aid 
recruitment by increasing geographical coverage (Thunberg \& Arnell, 2021). Research on non-disabled young people suggests that, notwithstanding technical issues, online interviewing makes it easier to divulge personal experiences, because of the physical distance between respondent and researcher (Weller, 2017). At the same time, being in the familiar surroundings of one's own home is likely to have a positive effect on interviewing (Stafford, 2017). Research indicates that video interviews do not reduce data quality (Jenner \& Myers, 2018), and that they often represent the preferred mode of choice among respondents (Archibald et al., 2019). It is therefore imperative to ascertain whether online platforms are a feasible research tool that can give voice to disabled young people whilst removing barriers to participation.

Drawing on our recent experience with the Educational Pathways and Work Outcomes longitudinal study, we provide initial answers to these methodological questions. Our methodological reflections are of wider relevance, providing insights for qualitative researchers conducting research during the COVID-19 pandemic.

\section{The Educational Pathways and Work Outcomes Longitudinal Study}

The Educational Pathways and Work Outcomes study is part of a 3-year research project that explores the association of adolescent disability with educational and occupational disadvantage in England. The study has a longitudinal research design, with a first wave of interviews with disabled young people at age 15/16 before GCSE examinations ${ }^{2}$, and a second wave approximately one year later. The study received full ethical approval from the Humanities \& Social Sciences Research Ethics Committee at the University of Warwick. 
We aimed to collect a sample of 50 disabled Year 11 students (15-16 years old) from mainstream schools in England, stratified by parental social class and impairment/condition. Such a sample would allow us to understand the influence of parental social class on young people's lived experiences and educational progress, and to explore differences by impairment/condition. We sought to distinguish between two broadly construed social class categories (working-class and middle-class), using information on parental occupational and educational attainment. We focused on three types of impairments/conditions: autism, dyslexia, and mobility difficulties. Recruitment spanned from March to August 2021. Study members received a $£ 20$ voucher for their first interview.

The pandemic necessitated substantial amendments to our research plan, which had been formulated before the first COVID-19 outbreak. In the following sections, we describe and reflect on our modified recruitment and interviewing strategies.

\section{Gaining Access}

\section{Recruiting through Schools}

Our original plan was to approach mainstream schools in the West Midlands (a metropolitan county in western-central England), building rapport with SENDCos through face-to-face meetings. However, the lockdown meant that all communications had to take place online. We sent personalised emails to SENDCos, explaining study aims and asking them to share details with students that met the sampling criteria. Follow-up reminders included a policy briefing with results from the broader project, emphasising the societal value of our study.

The vast majority of SENDCos never responded to our emails, mirroring experiences of other disability researchers (Williams, 2020). Some declined participation, raising personal workload concerns and/or heightened anxiety among disabled students due to the pandemic. 
Responses occasionally indicated the presence of ableist assumptions surrounding students' competency to take part. That is, we felt that gatekeepers would have reacted differently on a project focusing on non-disabled young people.

Given the very high levels of non-response in the West Midlands, we broadened our geographical remit, emailing approximately 500 schools from 6 English regions. This was made possible by the online method that kept travelling costs and time requirements at a minimum. There were no substantial differences in responses by region, although SENDCos contacted towards the end of the academic year appeared more likely to share information with students. This is likely linked to a reduction in workload pressures during that time.

This recruitment method was time-consuming and had very limited success, yielding only 8 study members, amounting to only one fifth of our final sample. We had originally hoped that school recruitment would give access to students experiencing varying levels of difficulties linked to their disabilities. However, it soon became evident that gatekeepers tended to impose their own boundaries in the investigation (Abrams, 2010; O'Reilly et al., 2013). Study members recruited through schools spoke about being "selected" by teachers and were often particularly articulate and high achieving. It is impossible to draw conclusions about this issue without information about the entire student cohort available to SENDCos. However, the performance of participants recruited through schools was substantially higher than the average performance of disabled students of this age in England (Chatzitheochari \& Platt, 2019), suggesting that they were likely selected to showcase exemplar performance, serving as figureheads for their school.

\section{Recruiting through youth charities, Disabled People's Organisations, and foodbanks}

Given the limited success of school recruitment, we focused our attention to youth charities and Disabled People's Organisations (DPOs). We had hoped to stay away from this 
recruitment method, considering that it would possibly give access to young people whose families are more educated and informed, actively tackling barriers linked to their child's impairments and conditions. We subsequently emailed a very high number of youth charities and Disabled People's Organisations (DPOs). We also authored two pieces for an awardwinning blog on special educational needs to spell out the aims and value of the study to the general public. These pieces were greatly appreciated by youth charities and DPOs, which regularly share research findings with their members.

Youth charities and DPOs were very keen to support the project, regularly distributing information on newsletters and social media. This method proved to be highly effective. We received more than 40 requests from parents of young people. Few of these did not fit our sampling criteria, while others went silent after initial contact. Generally, our project was met with great enthusiasm and little hesitancy from parents, who appreciated the impact that it could have on future generations.

In an attempt to boost recruitment of socio-economically disadvantaged young people, we also emailed/phoned several foodbanks and youth centres. Unfortunately, we did not manage to establish relationships with the majority of these gatekeepers, likely due to the reduced working patterns of staff/volunteers during lockdown measures.

\section{Sample Size and Composition}

Despite our hard efforts, we did not succeed in collecting a sample of 50 participants. Our final sample consisted of 35 young people.

The sample was characterised by a social class imbalance, with only around a quarter of the sample from the lower end of the social class spectrum, which does not align with statistics surrounding the socio-economic profile of students with our 3 conditions of interest 
in England (Parsons \& Platt, 2013). This imbalance can be partly attributed to lockdown and social distancing measures, which did not allow us to employ common strategies for accessing hard-to-reach populations such as physical presence in spaces likely to be frequented by disadvantaged families (e.g., food banks, youth centres) and development of long-term partnerships and good relationships with key gatekeepers such as SENDCos and youth workers. We felt that our efforts to build these connections via telephone and email were not as successful as physical co-presence within these spaces would have been. Similarly, recruitment through DPOs was less likely to reach disadvantaged young people during those unprecedented times, as a result of their limited access to the internet and/or technology.

There were several participants who had more than one impairment/condition of interest. 23 study members identified as autistic and 15 as dyslexic. There were only 7 study members who reported they had mobility difficulties ${ }^{3}$. This may be due to young people with higher support needs being less likely to attend mainstream school settings, as well as difficulties around interview accessibility, a topic discussed in later sections.

Although we did not achieve our intended sample size and composition, we felt that data saturation was reached, with common themes and patterns emerging through young people's accounts. However, the smaller than planned sample size necessitated systematic efforts to keep attrition at a minimum in Wave 2. Aside from regular email contact with study members, we introduced a biannual newsletter sharing project news and findings. Following the completion of Wave 1 fieldwork, we also decided to collect interviews from parents/guardians as this would allow us to better answer our research questions with minimal time investment and no additional financial cost. We felt that this additional study 
element further enhanced study members' trust and commitment to the study, potentially contributing to cohort maintenance.

\section{Interviewing}

Semi-structured interviews were loosely biographical in nature, allowing young people to freely narrate their biographies whilst highlighting events, people, and places of significance. Study members were given a choice between telephone or online interviews in line with best practice in the field (Ison, 2009). For online interviews, participants were asked to choose the platform best accommodating their needs. A major benefit of online interviews was that participants were able to utilise assistive software to make their interview more accessible e.g., enabling captioning/subtitles, modifying volume, and/or applying screen lighting and magnification. As Stafford (2017: 611) notes, 'providing participants choice and control in how they want to complete the [interview] seems crucial in maximising their participation'. Thirty-one interviews were conducted online via Zoom, Microsoft Teams or Google Meet, while four were conducted over the phone. Study members were generally very familiar with these online communication platforms, partly due to their use during the extended period of home-learning. Only two participants required support from their parents in setting-up their interview. Finally, it is worth noting that phone interviews involved some of the most socioeconomically disadvantaged study members, highlighting the importance of providing multiple means of participation to achieve a diverse sample.

\section{Ensuring accessibility and building rapport}

Our aim was to embrace an accessible, inclusive, and flexible data collection method. We first sent young people a short video of the interviewer introducing the study. The aim was for participants to become familiar with the interviewer and their style of talking in advance 
of "meeting" them online (see Strafford, 2017 and Harrington \& Foster, 2013 on the importance of providing participants with clear accessible information about the research process in advance). Recognising young people as experts in their own lives, we then decided to arrange pre-interview meetings with them and their parents instead of making assumptions about their abilities and needs based on their age and impairment(s)/condition(s) (Teachman \& Gibson, 2013).

Pre-interview meetings were conducted online or over the phone, lasting approximately 20-30 minutes. These meetings provided us with a better understanding of the young person, their condition(s), and communication preferences. Participants and their parents discussed any challenges they could foresee in taking part, and adjustments that could be made to the interview process.

We sought to ensure a person-centred interview approach. Adjustments included allowing participants to sit off screen or keep their cameras off, simplifying interview questions for those with learning disabilities, allocating greater time for participants with communication difficulties, and collecting data over several interviews to accommodate those who fatigue easily, experience pain or concentration difficulties. Additionally, pre-interviews provided contextual information about the young person, serving as valuable conversation openers for the interview, and enabling us to adjust content in line with the young person's experiences (Teachman \& Gibson, 2013).

Overall, the introductory video and pre-interview meetings were very well received, helping us build greater rapport with study members and their parents (Bushin, 2007; Jenkin et al., 2020; MacDonald \& Greggans, 2008). Forming trusting relationships is particularly 
important for projects of this type that focus on sensitive topics and have a longitudinal component, thus requiring participants' longer-term commitment.

\section{The Role of Parents in the Interview Process}

In line with our aim to ensure a fully inclusive method, we asked study members and their parents to decide whether they would like a parent/guardian to be present during their interview. While in most instances this was a joint decision made by the young person and their parent/s, in a rare few it was a decision made solely by parents due to concerns relating to welfare, independence, confidentiality, accessibility and/or perceived lack of competence on behalf of the young person. Two thirds of young people $(n=23)$ participated in the interview independently. To some extent, this is a result of our employed interview modes that did not require parents to accompany young people to a venue or play hosts/welcome the researcher into their homes. It was also evident that the pre-interview mettings had made parents more trusting and comfortable with the project whilst putting young people at ease about participating independently. Independent interviews aided disclosure, enabling study members to speak more freely about difficult and sensitive issues surrounding family relationships and their conditions/impairments. It is telling that some participants took further measures to ensure that no one was listening during the interview. These included moving location, closing the door, or plugging in their headphones.

Twelve young people participated in the interview in the presence of their parent/guardian and, in one instance, their teacher. There were different reasons for the decision to have someone else present e.g., to help communicate questions, maintain the young person's attention, provide emotional support, and/or further clarify answers. On certain occasions, parents of autistic young people were instrumental for interview success, 
planning the interview at a time of reduced schoolwork and stress and being present to manage emotions and/or concentration if needed.

Some parents simply sat in the background, while others sat next to the young person, taking a more active role in the interview. The presence of parents was particularly helpful in cases where participants had higher support needs as a result of learning difficulties, ensuring accessibility by occasionally communicating questions in a simpler manner. Additionally, there were instances where parents added useful contextual details around some very brief answers provided by participants.

However, there were times where parental presence was disruptive for the interview process and for building rapport with the young person. Similar to others (Bassett et al., 2008; Bushin, 2007), we found that parents sometimes interrupted interview flow by intervening and seeking to speak on the young person's behalf. Jenkins et al. (2020) have noted that the presence of a family member in an interview may overshadow or even silence the voices of disabled children. Indeed, there were a few instances where parents openly questioned their child's ability to understand or respond to the questions, seeking to answer on their behalf. It was therefore necessary to manage parents in order to ensure that the young person remained at the forefront. This involved reducing eye contact with parents, expressing concerns relating to the recording of two simultaneous voices, directing questions at the young person through use of their name, touching upon subjects that the young person may be more knowledgeable about, and/or coming up with a distraction for parents, as suggested by Bushin (2007: 247). It was challenging to employ these techniques in an online setting, as it was harder to interrupt through physical body language and hand gestures or talk over parents than it would have been in a face-to-face interview. 
The impact of parental presence was made apparent in an interview with an autistic male. He started his interview with his mother sat in the room beside him and was initially rather guarded and unresponsive. However, when his mother decided to leave the room, aware that her son may speak more freely without her presence, he began talking more openly and became markedly more responsive. This is in line with the observations of other researchers, who have similarly noted that teenagers' narratives quickly changed when parents entered the room, closing down conversation quickly (MacDonald \& Greggans 2008).

\section{Making Voices Heard in Online Settings}

The interview consisted of around 25 questions. Interview length ranged from 45 to 90 minutes. To increase uptake, young people were asked to choose the time of their interview with most opting for an evening/weekend. To put young people at ease, we started the interview with warm-up questions about school, family, and personal interests. Our main questions focused on impairments/conditions, school experiences, educational and occupational expectations, and plans for after GCSE examinations. An interview schedule was only loosely drawn upon to allow participants to freely articulate their biographies. Participants were familiar with our questions, having received an information pack via email prior to the interview. This included an indicative list of questions along with a few preparatory activities and exercises (Stafford, 2017), that is, a timeline activity (plotting out where they would like to see themselves in 10 years' time) and a support network diagram (identifying people/sources of support in their lives). We also included a 'social story' (Harrington and Foster, 2013) tailored particularly to young autistic people. The 'social story' 
showed what would happen in the interview e.g., who the researcher was and what they looked like, what they would be asked about and how long the interview would last.

While some young people were very comfortable narrating their biographies and lived experiences of disability, others were more hesitant, requiring regular prompting and reassurance. We did not discern systematic differences in responding style by condition/impairment type and/or stated level of support needs. Personality differences were no doubt at play. However, we noted that young people who had previous experience with counselling practices were more at ease, already familiar with being asked about their experiences and being listened to.

Interjection of occasional questions was used for prompting. We avoided excessive questioning (Cameron, 2005), aiming to encourage participants to speak freely throughout the process (Thomson \& Rudolph, 2000). We were keenly aware of the importance of "tolerat[ing] silences and hold[ing] one's tongue" (Wilson \& Powell, 2001: 51) when seeking to access young people's experiences. This is invariably more difficult in online settings. Participants were occasionally unsure of what was happening during silences, with some asking whether the researcher was still there, concerned that the signal had been lost or that the researcher was no longer listening. Giving visual cues was effective in most cases. In contrast, prompting was more complicated in phone interviews where the absence of visual cues meant that the researcher often interrupted or spoke over the participant.

There were a few cases where unstable internet connections interrupted the flow of the interview and the level of rapport between researcher and young person (Weller, 2017). This issue was usually resolved relatively quickly, and often acted as a helpful bonding exercise, 
perhaps due to the interviewer and interviewees' lack of technical expertise. Where unstable connections persisted, we reverted to telephone interviews, keeping the video call open on screen to retain visibility.

Another challenge related to the perceived difficulty of maintaining participants' attention. The interviewer occasionally felt that the lack of physical presence meant that participants were easily distracted due to lower levels of accountability. However, it could also be argued that what was interpreted as lack of attention and drop in focus was indicative of a greater share of power afforded to disabled young people in online settings. Young people were no doubt more easily able to divert attention elsewhere and change the direction of conversation with little interruption from the interviewer. Indeed, this could have been the result of a desire to avoid a certain topic rather than respondent fatigue or lack of attention.

Following interview completion, we sent participants their interview transcripts, inviting them to edit or add clarifications if they so wished. Participants were encouraged to do this either independently or with the support of a parent. It was essential to provide participants with autonomy over their personal data and to ensure that those who found it difficult to process questions under pressure were accurately depicted in the study. Very few participants opted to amend their transcripts, suggesting that the majority felt satisfied with their responses. We also sought feedback about the interview process through an online survey sent to participants' email addresses. The overall lack of suggestions for improvement further confirmed our impression that study members appreciated the online medium. Indeed, most study members requested an online interview for Wave 2 of data collection, even if COVID-19 restrictions are no longer in place. Informal email feedback from several study 
members and/or their parents confirmed that the interview was enjoyable despite the difficult issues touched upon, boosting young people's self-esteem and confidence.

\section{Impairments/conditions and the online interviewing method}

Our interviewing methods were person-centred, tailored to young people's individual needs and preferences. To ensure accessibility and enhance data quality, we engaged with methodological literature specifically focusing on interviewing autistic, dyslexic, and physically disabled people.

A key concern was the extent to which interviewing would be efficient for eliciting the views and lived experiences of autistic young people. Indeed, it has often been argued that the use of interviews relating to personal experiences may be inappropriate for autistic people due to anxiety and difficulties associated with conveying emotion verbally (Goodall, 2018). Literature has also suggested that autistic young people may be additionally disconcerted by encounters with strangers and/or become unresponsive due to difficulty in responding to open-ended questions (Shepherd, 2015).

Our experience was markedly different. Although there was one instance where an autistic male repeatedly provided 'I don't know' answers, most autistic young people were readily able to share their experiences through the online medium. This may be partly due to our careful use of questioning, which aligns with suggestions that autistic people benefit from clear direct questions and avoidance of metaphors (Gaynor et al., 2020). Several participants stated that they felt happy they were being listened to, referring to how autistic people are usually misunderstood and silenced in school settings. We felt that pre-interviews were particularly helpful for putting autistic participants at ease, while the practice of keeping the camera off or focused elsewhere rendered the interview less intrusive and anxiety provoking. 
Overall, it could be argued that the use of the online medium gave voice to a population who may not always be amenable to conventional face-to-face interviewing methods. This accords with recent discussions surrounding communication benefits of online provisions for autistic people during the pandemic (Cassidy et al., 2021).

At the same time, it is likely that self-selection was at play, with young people who were comfortable with conversational methods more likely to take part in the study. Indeed, there were a few potential participants who eventually withdrew interest due to increased anxiety about the interview process. Self-selection may also be part of the explanation for the low numbers of participants with cerebral palsy. While study members with cerebral palsy readily shared information about their lives and required minimal interview adjustments, literature suggests that this population may find online communication more difficult due to additional barriers in understanding and/or interpreting (Ison, 2009). Whether online or offline, the interview method may be seen as exhausting, preventing young people from stepping forward and taking part. Scholars have consequently argued that the overwhelming reliance on interview methods has silenced the voices and opinion of this group (Ison, 2009). We were prepared to use alternative methods such as email interviews, which would give these participants the space and time to articulate their lived experiences (James, 2016). However, time and staffing constraints meant that such alternatives were not sufficiently communicated to potential participants at time of recruitment. Separate recruitment flyers and information packs emphasising the ways the interview could be adapted to meet the needs and preferences of participants with cerebral palsy could have aided recruitment of this group, ultimately leading to a more diversified interviewing approach.

\section{Discussion and concluding remarks}


This paper reflected on our experience starting a longitudinal study of disabled young people amidst the COVID-19 global pandemic. Rather than discussing all aspects of our research design, we focused on those most affected by social distancing and lockdown measures in place during the time of fieldwork, namely recruitment and interviewing.

To date, there has been little discussion on the effects of COVID-19 on recruitment of hard-to-reach populations for research. Our experience suggests that the pandemic exacerbated existing barriers implicated in the recruitment of these groups. The difficulties that we encountered in eliciting positive responses from school gatekeepers mirror experiences of researchers before the pandemic (Williams, 2020). However, we felt that school gatekeepers' unwillingness to support research projects like ours intensified during the pandemic due to heightened workloads and anxiety experienced by themselves and young people alike (Ashbury et al., 2021, Kim \& Ashbury 2020). Lockdown and social distancing measures meant that we had to exclusively rely on emails and phone calls to form trusting partnerships with school gatekeepers. It was therefore extremely difficult to effectively demonstrate the value of our study and the way research findings could benefit schools. Time and staffing constraints did not allow us to create specialised resources for these purposes. Future research projects may want to consider employing such resources to establish rapport and ease specialist gatekeepers' mistrust of the research process during periods when physical co-presence is not possible.

Similar to other researchers focusing on hidden and hard-to-reach populations, we ended up making use of several sampling techniques to achieve our sampling goals (Abrams, 2010; Ellard-Gray et al., 2015). Unlike school gatekeepers, DPOs, charities, and parents of disabled young people were very supportive of the project, agreeing to circulate recruitment 
information widely through their networks and social media. This allowed us to elicit a substantial response from potential participants. Like other research projects that recruited participants during the pandemic, we witnessed the power of social media for sampling purposes (Archer-Kuhn et al., 2021). At the same time, despite our initial misgivings about the highly selected sample of participants that we would reach through this recruitment method, we ended up with a more diverse group than the high achieving one recruited through schools.

We only managed to achieve $70 \%$ of our targeted sample size, which aimed to provide us with "maximum variation" of perspectives and differences (Patton, 2002). At first glance, this could be interpreted as evidence against the efficiency of online recruitment methods for research with disabled and/or 'hard to reach' population groups. However, we maintain that this needs to be interpreted with caution: Our project sought to recruit from a specific cohort of disabled young people who were experiencing ongoing uncertainty surrounding alternative arrangements for GCSE examinations whilst navigating online learning and a national lockdown. Similarly, we only focused on three specific conditions, and our fieldwork had to be completed by early August 2021 prior to GCSE results being published ${ }^{4}$, leaving us with only two school-free months. Research projects with less strict time constraints and broader inclusion criteria could potentially achieve targeted sample sizes through exclusive use of socially distanced recruitment methods.

We originally planned for our sample to be stratified by social class, in line with one of the project's comparative research questions. However, we did not manage to recruit comparable numbers of disabled young people from middle-class and working-class families. Our efforts to boost numbers of young people from working-class and disadvantaged 
backgrounds consisted of emails and phone calls to foodbanks and youth centers/charities that focused on these specific groups, emphasising the $£ 20$ voucher and the possibility of conducting the interview over the phone. This did not substantially alter the social class imbalance of our sample. The pandemic prevented us from using other strategies such as attending venues and physical spaces likely to be attended by disadvantaged young people. Additionally, due to time constraints and complexities of ethical approvals we were not able to follow other institutionalised routes such as contacting social services, local councils, and National Health Service providers. However, it should be noted that recruitment of such hardto-reach groups is a longstanding problem for qualitative longitudinal research (Ellard-Gray et al., 2015, Abrams, 2010), suggesting that our failure cannot be solely attributed to the current pandemic. As Purdie-Vaughns \& Eibach (2008) have noted, groups who have intersecting marginalised identities are relegated to a position of intersectional invisibility within their communities. These groups are more likely to mistrust the research process and are particularly difficult to access due to their lack of support networks (Ellard-Gray et al., 2015). While this issue is beyond the scope of our paper, we encourage qualitative researchers to pay more attention to sampling of these groups in future research focusing on hard-to-reach populations and/or account for their absence from analytic samples. Such an endeavour is necessary to uphold claims of research inclusivity.

Our overall fieldwork experience negated longstanding assumptions surrounding the inability of disabled young people to engage with conversational methods (Bassett et al., 2018). We found that, when used sensitively, this method can provide a useful platform through which young people can narrative their lived experiences of disability (Preece \& Jordan, 2010; Shepherd, 2015). Online interviews presented some challenges for the interviewer such as difficulty reading cues, interpreting emotions, prompting, and 
maintaining participants' attention. It is important to note that some of these communication challenges are experienced by disabled young people on a daily basis (Gaynor et al., 2020). It could therefore be argued that the online setting afforded disabled young people with a greater share of power and agency (Weller et al, 2017), an issue of utmost importance for qualitative methodologies.

We admit that it is impossible to know whether face-to-face interviews would have yielded better quality data. However, our online interviews produced rich narrative accounts, prompting us to endorse Weller's (2017) suggestion that they should not be seen as second rate to face-to-face interviews. Participants' feedback and preferences for online interviews in Wave 2 further reinforces this view and is in accordance with earlier research (Archibald et al., 2019).

A major advantage of online interviewing is the dramatic reduction of travel costs and of time required to conduct interviews. This provided us with the flexibility to allocate resources to cohort maintenance and impact activities, and to add new study elements (e.g., parental interviews) that allow us to better answer our original research questions. The latter has compensated for the smaller than planned sample size of our longitudinal study. At the same time, online interviewing has enabled us to broaden the geographical remit of our study, which is crucial for any study focusing on a hard-to-reach population. We therefore argue that online interviews should not be seen solely as a temporary solution among qualitative researchers but as having a wider and longer lasting value, with the potential to greatly influence future decades of research with children and youth, disabled people as well as other 'hard to reach' and/or vulnerable population groups. 
Throughout this study we have sought to give voice to young people whose lived experiences have frequently been overshadowed by those of their parents and health/medical professionals. As a generation who have grown up using digital technologies as a means of communication on a daily basis, greater exploration is needed into how online methods may be further incorporated into qualitative research projects with children and young people, during the pandemic and beyond. This paper demonstrates the potential of online methods in serving as an accessible platform through which young people may relatively comfortably share their voices, viewpoints and lived experiences.

\section{Notes}

1. A SENDCo is a teacher who coordinates in-school provision for disabled students and/or those with special educational needs.

2. The General Certificate of Secondary Education (GCSE) is the standard qualification exam undertaken by pupils in England and Wales at age 15/16, after two years of study. GCSE attainment is a major branching point in a young person's educational career and plays a critical role in determining post-compulsory education and employment pathways.

3. It should be noted that around half of participants also had additional disabilities that lay outside of our three disabilities of interest, this included e.g., learning disabilities, hearing impairments, dyspraxia etc.

4. Wave 1 data collection sought to document disabled young people's occupational and educational aspirations prior to them receiving information about their GCSE performance, hence this deadline for fieldwork completion.

\section{Acknowledgements}


We are grateful to the young people who agreed to be part of our study and generously gave their time to speak about their experiences. We also thank Jonathan Vincent for his guidance on recruitment and Melissa Chapple for her useful comments and advice.

\section{References}

Abrams, L.S. (2010). Sampling 'Hard to Reach' Populations in Qualitative Research: The Case of Incarcerated Youth. Qualitative Social Work,9(4), 536-550. https://doi.org/10.1177/1473325010367821

Archer-Kuhn, B., Beltrano, N.R., Hughes, j., Saini, M. \& Tam, D. (2021). Recruitment in response to a pandemic: pivoting a community-based recruitment strategy to facebook for hard-to-reach populations during COVID-19. International Journal of Social Research Methodology, https://doi.org/10.1080/13645579.2021.1941647

Archibald, M. M., AmbagtSheer, R.C., Casey, M.G., \& Lawless, M. (2019). Using Zoom videoconferencing for qualitative data collection: Perceptions and experiences of researchers and participants. International Journal of Qualitative Methods, 18, 1-18. https://doi.org/10.1177/1609406919874596

Ashbury, K., Fox, L., Deniz, E., Code, A., \& Toseeb, O. (2021). How is COVID-19 affecting the mental health of children with special educational needs and disabilities and their families? Journal of Autism and Developmental Disorders, 51, 1772-1780.

https://doi.org/10.1007/s10803-020-04577-2

Bassett, R., Beagan, B.L., Ristovski-Slijepocevic, S., \& Chapman, G.E. (2008). Tough teens: The methodological challenges of interviewing teenagers in research participants. Journal of Adolescent Research, 23(2), 119-131. https://doi.org/10.1177/0743558407310733

Beresford, B. (1997). Personal accounts: Involving disabled children in research. Social Policy Research Unit.

Brady., G \& Franklin, A (2019). Challenging dominant notions of participation and protection through a co-led disabled young researcher study. Journal of Children's Services, 14(3), 174-185. https://doi.org./10.1108/JCS-03-2019-0016

Bushin, N. (2007). Interviewing with children in their homes: Putting ethical principles into practice and developing flexible techniques. Children's Geographies, 5(3), 235-251. https://doi.org/10.1080/14733280701445796

Cameron, H. (2005). Asking the tough questions: A guide to ethical practices in interviewing young children. Early Child Development and Care, 175(6), 597-610. https://doi.org/10.1080/03004430500131387

Campbell, A. (2008). For their own good: Recruiting children for research. Childhood, 15(1), 30-49. https://doi.org/10.1177/0907568207086834 
Carlsson, E., Patterson, B., Scott-Findlay, S., Ehnfors, M., \& Ehrenberg, A. (2007).

Methodological issues in interviews involving people with communication impairments after acquired brain damage. Qualitative Health Research, 17(10), 1361-1371.

https://doi.org/10.1177/1049732307306926

Cassidy, S., Nicolaidis, C., Davis, B., Des Roches, R., Eisenman, D., Onaiwu, M., Kapp, S., Kripke, C., Rodgers, J., \& Waisman, T. (2020). An expert discussion on autism in the COVID-19 pandemic. Autism in Adulthood, 2(2), 106-117.

Chatzitheochari, S., \& Platt, L. (2019). Disability differentials in educational attainment in England: primary and secondary effects. British Journal of Sociology, 70, 502-525. https://doi.org/10.1111/1468-4446.12372

Christensen, P., \& James, A. (2000). Research with children: Perspectives and practices. Routledge.

Clark, T. (2010). Gaining and maintaining access: Exploring the mechanisms that support and challenge the relationship between gatekeepers and researchers. Qualitative Social Work, 10(4), 485-502. https://doi.org/10.1177/1473325009358228

Cowie, H., \& Myers, C-A. (2021). The impact of the COVID-19 pandemic on the mental health and well-being of children and young people. Children and Society, 35, 62- 74. https://doi.org/10.1111/chso.12430

Ellard-Gray, A., Jeffrey, N., Choubak, M. \& Crann, S. (2015) Finding the hidden participant: Solutions for recruiting hidden, hard-to-reach and vulnerable populations, International Journal of Qualitative Methods, 14(5), 1-10 https://doi.org/10.1177/1609406915621420

Gaynor, Z., Alevizos, K \& Butler, J. (2020) IS THAT CLEAR?: Effective communication in a neurodiverse world, www.acrobat-global.com

Goodall, C. (2018). "I felt closed in and like I couldn't breathe": A qualitative study exploring the mainstream educational experiences of autistic young people. Autism and Developmental Language Impairments, 3, 1-16. https://doi.org/10.1177/2396941518804407

Halfon, N., Houtrow, A., Larson, K. \& Newacheck, P. (2012) The Changing Landscape of Disability in Childhood, The Future of Children, 22(1), 13-42.

https://doi.org/10.1353/foc.2012.0004

Harden, J., Scott, S., Backett-Milburn, K., \& Jackson, S. (2000). Can't talk, won't talk?: Methodological issues in researching children. Sociological Research Online, 5(2). https://doi.org/10.5153/sro.486

Harrington, C \& Foster, M (2013) Engaging young people with Autism Spectrum Disorder in research interviews, British Journal of Learning Disabilities 42: 153-161. https://doi.org/10.1111/bld.12037

Heath, S., Charles, V., Crow, G., \& Wiles, R. (2007). Informed consent, gatekeepers and gobetweens: Negotiating consent in child- and youth-orientated institutions. British Educational Research Journal 33(3), 403-17. https://doi.org/10.1080/01411920701243651 
Hill, M. (1997). Participatory research with children. Child and Family Social Work, 2, 171183. https://doi.org/10.1046/j.1365-2206.1997.00056.x

Holt, L., \& Evans, R. (2017). Geographies of children and young people: Methodological approaches. In T. Skelton L., Holt, R. Evans (Eds) Methodological Approaches. (pp. ix-xvi). Springer Nature.

Ison, N.L. (2009). Having their say: Email interviews for research data collection with people who have verbal communication impairments. International Journal of Social Research Methodology, 12(2), 161-172. https://doi.org/10.1080/13645570902752365

James, N. (2016) Using email interviews in qualitative educational research: creating space to think and time to talk. International Journal of Qualitative Studies in Education, 29(2), 150163. https://doi.org/10.1080/09518398.2015.1017848

Jenkin, E., Wilson, E., Campaign, R., \& Clarke, M. (2020). The principles and ethics of including children with disability in child research. Child Sociology, 34, 1-16.

https://doi.org/10.1111/chso.12356

Jenner, B.M., \& Myers, K.C. (2019) Intimacy, rapport, and exceptional disclosure: A comparison of in-person and mediated interview contexts. International Journal of Social Research Methodology, 22(2), 165-177. https://doi.org/10.1080/13645579.2018.1512694

Kirk, S. (2007). Methodological and ethical issues in conducting qualitative research with children and young people: A literature review, International Journal of Nursing Studies, 44, 1250-1260. https://doi.org/10.1016/j.ijnurstu.2006.08.015

Levine, R. (2007). Ethnographic studies of childhood: A historical overview. American Anthropologist, 109(2), 247-260. https://doi.org/10.1525/aa.2007.109.2.247

Liddiard, K., Runswick-Cole, K., Goodley, D., Whitney, S., Vogelmann, E. and Watts MBE, L. (2019). "I was excited by the idea of a project that focuses on those unasked questions":

Co-Producing disability research with disabled young people. Children and Society, 33, 154167. https://doi.org/10.1111/chso. 12308

Kim, L.E., \& Ashbury, K. (2020). "Like a rug had been pulled from under you": The impact of COVID-19 on teachers in England during the first six weeks of the UK lockdown. British Journal of Educational Psychology, 90, 1062-1083. https://doi.org/10.1111/bjep.12381

MacDonald, K., \& Greggans, A. (2008). Dealing with chaos and complexity: The reality of interviewing children and families in their own homes. Journal of Clinical Nursing, 17, 31233130. https://doi.org/10.1111/j.1365-2702.2008.02495.x

Meyer, H. \& Wilson, P. (2009) Sampling lesbian, gay, and bisexual populations, Journal of Counselling Psychology, 56: 23-31 doi:10.1037/a0014587

McDowell, L. (2001). 'It's that Linda again': Ethical, practical and political issues involved in longitudinal research with young men. Ethics, Place \& Environment, 4(2), 87100. https://doi.org/10.1080/13668790124226 
McLaughlin, J. \& Coleman-Fountain, E. (2019). Visual methods and voice in disabled childhoods research: Troubling narrative authenticity. Qualitative Research, 19(4), 363-381. https://doi.org/10.1177/1468794118760705.

O'Reilly, M., Ronzoni, P., \& Dogra, N. (2013). Research with children: Theory and practice. SAGE.

Parsons, S. and Platt, L. (2013). Disability among young children: Prevalence, heterogeneity and socio-economic disadvantage, Centre for Longitudinal Studies.

Patton, M. Q. (2002) Qualitative Research and Evaluation Methods. SAGE.

Preece, D., \& Jordan, R. (2010). Obtaining the views of children and young people with autism spectrum disorders about their experience of daily life and social care support. British Journal of Learning Disabilities, 38, 10-20. https://doi.org/10.1111/j.1468-

3156.2009.00548.x

Punch, S., \& Graham, E. (2017). Interviewing Children at Home: Exploring the Use of Individual and Focus Group Interviews. In T. Skelton L., Holt R. Evans (Eds) Methodological Approaches (pp. 199-222). Springer Nature.

Purdie-Vaughns, V. \& Eibach, R. (2008) Intersectional invisibility: The distinctive advantages and disadvantages of multiple subordinate-group identities, Sex Roles, 59, $377-$ 391

Qvortrup, J. (2001). A voice for Children in statistical and social Accounting: A plea for children's rights to be heard. In A. James, \& A. Prout (Eds.) Constructing and Reconstructing Childhood: Contemporary Issues in the Sociological Study of Childhood (pp. 85-103). Routledge.

Rettie, R. (2009). Mobile phone communication: Extending Goffman to mediated interaction. Sociology. 43(3), 421-438. https://doi.org/10.1177/0038038509103197

Shepherd, J. (2015). 'Interrupted interviews': Listening to young people with autism in transition to college. Exchanges: the Warwick Research Journal. 2(2), 249-262. https://doi.org/10.31273/eirj.v2i2.114

Stafford, L. (2017). 'What about my voice': Emancipating the voices of children with disabilities through participant-centred methods. Children's Geographies, 15(5), 600-613. https://doi.org/10.1080/14733285.2017.1295134

Teachman, G., \& Gibson, B. E. (2013). Children and youth with disabilities: Innovative methods for single qualitative interviews, Qualitative Health Research 23(2), 264-274. https://doi.org/10.1177/1049732312468063

Thompson, C., \& Rudolph, L. (2000). Counselling children. Wadsworth. 
Thunberg, S., \& Arnell, L. (2021). Pioneering the use of technologies in qualitative research - A research review of the use of digital interviews. International Journal of Social Research Methodology. https://doi.org/10.1080/13645579.2021.1935565

Topping, M., Douglas, J., \& Winkler, D. (2021). General considerations for conducting online qualitative research and practice implications for interviewing people with acquired brain injury. International Journal of Qualitative Methods, 20, 1-15.

https://doi.org/10.1177/16094069211019615

Watson, N. (2012). Theorising the lives of disabled children: How can disability theory help?. Children and Society, 26(3), 192-202. https://doi.org/10.1111/j.1099$\underline{0860.2012 .00432 . x}$

Weller, S. (2017) .Using internet video calls in qualitative (longitudinal) interviews: Some implications for rapport. International Journal of Social Research Methodology 20(6), 613625. https://doi.org/10.1080/13645579.2016.1269505

Whitehurst, T. (2007). Liberating silent voices - Perspectives of children with profound \& complex learning needs on inclusion. British Journal of Learning Disabilities, 35, 55-61. https://doi.org/10.1111/j.1468-3156.2006.00405.x

Wickenden, M. \& Kembhavi-Tam, G. (2014). Ask us too! Doing participatory research with disabled children in the global south. Childhood 21(3), 400-417.

https://doi.org/10.1177\%2F0907568214525426

Williams, P. (2020). 'It all sounds very interesting, but we're just too busy!': Exploring why 'gatekeepers' decline access to potential research participants with learning disabilities. European Journal of Special Needs Education, 35(1), 1-14. https://doi.org/10.1080/08856257.2019.1687563

Wilson, C., \& Powell, M. (2001). A guide to interviewing children: Essential skills for counsellors, police, lawyers and social workers. Allen and Urwin. 